\title{
Health Behaviors in the Service Sector: Substance Use Among Restaurant Employees
}

\author{
Amanda Michiko Shigihara, $\mathrm{PhD}$ \\ California State University Sacramento, Sacramento, California, United States
}

Contact: shigihara@csus.edu

\section{Abstract}

Restaurant workers in the United States exhibit high levels of alcohol and drug use. However, there is a scant amount of qualitative research uncovering how and why restaurant employees use and abuse legal and illegal substances. Examining restaurant workers' self-reported risky health behaviors is important for improving employee and occupational quality of life. The purpose of this article is to investigate the health behaviors of restaurant workers and pathways to such outcomes. Specifically, this article explores the question of what social conditions and processes within restaurants relate to employee adverse health behaviors. Drawing on qualitative data collected between 2009 and 2014, this article focuses on a case study of restaurant employees, detailing their substance use and the ways in which they discuss and talk about taking health risks. An analysis of 52 in-depth, semistructured interviews with restaurant workers broadens the theoretical explanation for deviant health behaviors in the service sector. Results indicate that workplace characteristics-such as occupational socialization, norms and values, job stress and coping mechanisms, social networks and friendships, and personnel policies-permit and encourage substance use and risky health behaviors. Research implications include underscoring service industry adverse health behaviors and recommendations for positive social change in terms of personal, social, and job-related well-being.

Keywords: restaurant employees; risky health behaviors; substance use; occupational norms; social networks; workplace policies; professional back places; well-being

Date Submitted: June 6, 2019 | Date Published: April 82020

\section{Recommended Citation}

Shigihara, A. M. (2020). Health behaviors in the service sector: Substance use among restaurant employees. Journal of Social, Behavioral, and Health Sciences, 14, 37-52. https://doi.org/10.5590/JSBHS.2020.14.1.04

\section{Introduction}

Employing approximately 15.3 million people (with an expected increase of 1.6 million by 2029), the restaurant industry makes up 10\% of the U.S. workforce and is the second largest private-sector employer in the nation (National Restaurant Association [NRA], 2019). Moreover, nearly 60\% of all U.S. adults have worked in the restaurant industry during their lifetime, and more than $33 \%$ of people in the United States had their first job experience in one of the over 1 million U.S. restaurant establishments (NRA, 2019). These statistics not only highlight the far reach of the U.S. restaurant industry, but also suggest that working in a 
restaurant is a rite of passage for many people. Along with the advantageous economic side of the restaurant industry, that is, more than $\$ 860$ billion in sales or $4 \%$ of the U.S. gross domestic product (NRA, 2019), studies indicate adverse health behaviors among foodservice employees. For example, restaurant workers engage in heavy alcohol consumption and illicit substance use (Grandey et al., 2019; Hight \& Park, 2018; Hoffman et al., 1996; Pidd et al., 2014; Pizam, 2010, 2012). Reporting on combined U.S. data from 2008 to 2012, research shows that in comparison to other employees, foodservice employees have the highest pastmonth illicit drug use and past-year substance use disorders (abuse and dependency), and they ranked third highest for past-month heavy alcohol consumption (Bush \& Lipari, 2015).

Studies highlight that substance use among employees is linked to health issues and illnesses, driving while under the influence of substances, accidents and injuries on the job, poor service, lack of work cohesion, increased work and stress for coworkers and managers, liquor costs, absenteeism, high turnover rates, loss of productivity, and hiring and training expenses (Bush \& Lipari, 2015; Ghodse, 2005; Kaminski et al., 2019; Moore, 1998). Although scholars have documented high levels of substance use among restaurant employees, there is a dearth of qualitative research (particularly current research) examining how and why these workers participate in risky health behaviors, especially from a sociological perspective, which focuses on how human behavior is shaped by social structures, groups, relationships, and interactions. Attention on self-reported sociocultural processes within restaurants that may influence problem health behaviors is largely missing. This article attends to this oversight by qualitatively examining restaurant workers' adverse health behaviors and the ways in which they talk about taking health risks. The current study is important for understanding restaurant employees' various pathways to health risks and for providing positive social change recommendations to improve restaurant worker and industry well-being.

\section{Substance Use in the Workplace}

The work and occupations literature generally have two perspectives on the relationship between the workplace and substance use. The first perspective suggests that substance use precedes people's employment entrance (Paternoster et al., 2003). The second perspective posits that substance use succeeds employment entrance because of workplace factors, such as occupational norms, poor quality of the work, alienation, lack of control, and powerlessness (Ames \& Janes, 1992). Research suggests that job stress is a dominant contributor of and intensifies substance use among employees (Hight \& Park, 2019; Lehman \& Bennett, 2002). Other workplace factors that contribute to risky health behaviors include lax work settings, norms and values, little fear of formal sanctions, job dissatisfaction, substance accessibility, and inadequate prevention policies (Bryant, 1974; Frone \& Windle, 1997; Kitterlin, 2015; Trinkoff et al., 2000). Although employees may exhibit risky health behaviors prior to working or at the onset of their working years, this article addresses the factors within restaurants that encourage and exacerbate adverse health behaviors.

\section{Restaurant Work, Substance Use, Stress, and Social Networks}

Employees in the restaurant industry exhibit sizable levels of substance use as compared to workers in other industries (Hight \& Park, 2018; Hoffman et al., 1996; Pizam, 2010, 2012). Researchers also reveal considerable alcohol and drug use among kitchen employees (Fine, 1996; Giousmpasoglou et al., 2018). Historically, those working as servers, bartenders, or other employees in eating and drinking places display high alcohol- and tobacco-related mortality and health issues (Dimich-Ward et al., 1988; Karasek \& Theorell, 1990; Leigh, 1991; Leigh \& Jiang, 1993). Current research on foodservice employee mortality is largely absent, but studies indicate that substance use and abuse is linked to a variety of detrimental health consequences, such as cardiovascular disease and cirrhosis (Degenhardt \& Hall 2012; Horgan et al., 2001). Additionally, in 2017 alone, almost 36,000 people died of alcohol-induced causes and nearly 74,00o people died of drug- 
induced causes (Kochanek et al., 2019). Furthermore, on average, there is one alcohol-impaired-driving fatality every 50 min or 29 deaths per day (National Highway Traffic Safety Administration, 2017).

Studies indicate that availability is a factor of alcohol consumption for restaurant-affiliated individuals (Buvik \& Scheffels, 2019; Larsen, 1994; Mandell et al., 1992). Moreover, research suggests that the probability of heavy drinking increases when workers score high on an extraversion rating scale (Kjaerheim et al., 1996), socialize with coworkers (Moore et al., 2009), and drink after work (Kjaerheim et al., 1995; Moore et al., 2012). Kjaerheim and colleagues (1997) pointed out that stress mediated by the inability to relax after work was associated with heavy drinking, and Nusbaumer and Reiling (2002) found that people who enjoy social settings, mixing drinks, and drinking on the job chose workplaces that serve alcohol. Other quantitative research descriptively shows that restaurant workers are more likely to use illicit drugs than employees are in other jobs (Anthony et al., 1992; Kaminski et al., 2019).

Scholars indicate that when social or environmental conditions are perceived or appraised as stressful, people smoke, drink, or use other substances to alleviate stress (French et al., 1962; Lazarus, 1966; McGrath, 1970). Research underscores that jobs with high demands but low decision latitude (e.g., restaurant jobs) predict mental strain (Karasek, 1979; see Whyte, 1948). Restaurant employees are required to maintain a fast pace while managing and balancing emotions, behaviors, and stress (Gatta, 2002; Giousmpasoglou et al., 2018; Hight \& Park, 2018; Shigihara, 2015, 2018a, 2019). Despite research on restaurant employees, there remains a lack of studies concentrating on restaurant workers' self-reported use of substances, let alone on a wide variety of restaurant industry employees (i.e., line cooks, chefs, bussers, hosts, servers, bartenders, and managers). Most studies do not examine how and why substance use occurs or explore the sociocultural characteristics of restaurant work that influence risky health behaviors.

Some scholars have analyzed how social networks relate to risky health behaviors. The literature suggests that social networks can influence group members positively and negatively. On one hand, social networks can provide positive senses of attachment, companionship, and bonding (Rook, 1990). On the other hand, shared group norms can promote risky health behaviors (Moore et al., 2012; Pampel, 2006). Similar to scholarship on stress, the social networks literature suggests that social groups promote coping styles (Holahan \& Moos, 1987; Lee \& Craft, 2002). Berkman and colleagues (2000) indicate the salience of exploring conditions that influence social network development and how social networks influence health outcomes, both of which are aims in this study.

Although people generally understand that cigarettes, excessive alcohol consumption, and illicit drug use can lead to negative health effects, research shows that restaurant workers exhibit high rates of substance use. However, currently, there is limited understanding about how and why restaurant workers partake in risky health behaviors, perceive workplace stressors, and engage in coping mechanisms (Wesolowski, 2016). The purpose of this article is to investigate the health behaviors of restaurant workers and pathways to such outcomes. This study examines social conditions and processes within restaurants and related health issues. Doing so advances the understanding of adverse health behaviors among restaurant workers.

\section{Professional Back Places}

Over 50 years ago, Goffman (1963) proposed the term back place in his seminal book Stigma. He defined back place as a space "likely to provide an atmosphere of special piquancy" that is entered voluntarily or involuntarily and "where persons of the individual's kind stand exposed and find they need not try to conceal their stigma, nor be overly concerned with cooperatively trying to disattend it" (p. 81). Examples of places that Goffman indicated as inspiring little concern of stigma are carnivals, mental hospitals, and the beats of prostitutes. While Goffman described a back place as an area that permits ease among members, he also contended that people in back places could be discredited if outsiders entered. 
More recently, scholars have expanded Goffman's notion of back places and interchangeably used the terms back place and backspace. For instance, Redmon (2003) framed his research on Mardi Gras in New Orleans, Louisianna, with the concept of backspaces. According to Redmon, backspaces permit people a liminal license for norm transgressions and playful deviance, such as public nudity or sex acts. Moreover, Redmon argued that backspaces "shield individuals from community members, the criminal justice institution, and/or the government, all of which threaten to arrest, sanction, discipline, or stigmatize their performances" (p. 28). Redmon specifically labeled "appropriated buildings used by anarchists, temporary autonomous zones, Mardi Gras, Spring-Break, chat rooms, pop-cultural festivals, concerts, smoke-outs on 4:20, carnivals, raves, 1-900 sex lines, S/M bars, and dance clubs where amateur stripping occurs" as backspaces (p. 29). Ending his article, Redmon called for future research on backspaces in the realms of "visual sociology, entertainment, leisure, performances, and fun" (p. 50). Importantly, this article investigates service-sector employment that pertains to entertainment, leisure, performances, and fun, as well as hospitality.

Building upon Goffman (1963) and Redmon (2003), I (Shigihara, 2018b) developed the term professional back places or "workplaces where employees, for the most part, can stand exposed, do not have to conceal stigmas, and feel at ease among their coworkers. They not only allow for temporary norm transgressions, but also long-term ones" (p. 512). I found that restaurants have "workplace shields" that safeguard employees against community members and the criminal justice system. Specifically, I discovered that the workplace shields of "socialization," "friendships," and "personnel policies" provided opportunities for employee theft and protection against social disgrace, rebuke, and shame. Workplace socialization is all the ways in which people learn (and attempt) to align their behaviors with occupational norms; workplace friendships are the peer groups that teach (and encourage) occupational norms; and workplace personnel policies, formal and informal, are the guidelines that govern occupational norms (Shigihara, 2018b). In sum, I argued that restaurant employees learn acceptable and unacceptable norm transgressions as they spend time in and around restaurants, and restaurants directly as well as indirectly assist in and structurally guide employee norm transgressions. Within this article, I adopt this theoretical framework of professional back places to examine and explain risky health behaviors among restaurant employees.

\section{Method}

\section{Entrée, Sample Recruitment, and Data Collection Techniques}

For 13 years, I worked in several full-service restaurants in different locations as a server and bartender. Before this study began, I worked 8 years in full-service restaurants. My complete membership role (Adler \& Adler, 1987) assisted in research-setting entrée, which also helped yield field observations, key informants, and interview questions. After the University of Colorado Boulder's Institutional Review Board granted research approval, I began a systematic ethnographic study. This article draws on qualitative data collected over a 5-year period (2009-2014).

Throughout these 5 years, I used several data collection techniques, including participant observation, fieldnotes, interviews, memos, and follow-up interviews. A range of methods grants diverse and rich information, comparisons between personal accounts and observable behaviors, and thicker description than only one method would provide (Warren \& Karner, 2010). Despite engaging in multiple qualitative methods, I focus on the in-depth, semistructured interview data in this article to underscore the restaurant employees' accounts of risky health behaviors. I located participants for interviews with the technique of snowball sampling (Sudman \& Kalton, 1986). In other words, I first interviewed close contacts and then referrals. Snowball sampling is especially useful when discussing unconventional behaviors (Biernacki \& Waldorf, 1981). Although I neither recruited participants based on alcohol or drug use nor specifically asked them about illicit behaviors, substance use and health risks inductively emerged as major themes. 
I conducted 52 semistructured, in-depth interviews with restaurant employees. Prior to the interviews, participants chose interview locations (e.g., coffee shops) and pseudonyms. The interviews lasted between 90 min and $4 \mathrm{hr}$, were face-to-face, and were audio-recorded. In accordance with Charmaz (2008), the interview guide was composed of several thematic questions formed from participant observation and adjusted as concepts and ideas emerged. This approach permits interview guide adjustment, follow-up questions, and category testing in the field (Strauss, 1987). Additionally, this type of inductive research leads to social pattern development and theory building (Becker \& Geer, 1960).

Broadly, the interview guide consisted of questions about life histories, daily activities, workplace structure and procedures, occupational norms and values, social networks and friendships, wages and benefits, as well as thoughts, feelings, and behaviors. Examples of the interview guide questions that led to the participants' responses about substance use and health risks were "Do you socialize with your coworkers during and/or outside of work?" "Are employees allowed to eat and/or drink at your job?" "What does coworker and customer treatment look like to you?" "Can you describe some stressful workplace experiences?” "How do you deal with problems at work?" and "What are some of the most outrageous or unusual experiences you have had while working in restaurants?” During the interviews, I also used follow-up questions to probe participants for further information, explanations, clarifications, and examples.

\section{Participants}

The sample included 24 male and 28 female bussers, hosts, food runners/expeditors, servers, bartenders, cooks/chefs, and managers between the ages of 18 and $48(M=26.6)$. Participants worked between 2 and 25 years $(M=9)$ in full-service restaurants in California and Colorado. The majority of the interviewees worked in two or more different restaurants, which resulted in them disclosing experiences from well over 70 restaurants. In addition, the participants generally worked in different employment positions and in several full-service independent and chain restaurants. Employees in the sample often held more than one employment position simultaneously. For example, some managers were also bartendersor servers. Participants typically entered restaurant work in hourly paid positions, gained experience in various positions, and some entered salaried positions.

Table 1 displays participant sociodemographic characteristics: sex/gender, race, age, highest level of education completed, income, employment status, and number of years worked. Half of the sample was White, and the other half was Black, Asian, Hispanic/Latino, or mixed. The mixed-race category included participants who reported racial combinations of White with Black, Asian, Hispanic/Latino, Native American, and/or MiddleEastern. Growing up, half the interviewees reported a middle-class socioeconomic status $(N=26)$, and the other half almost equally reported a working/lower class $(N=15)$ or middle/upper class socioeconomic status $(N=11)$. While one participant had only a high school diploma, the vast majority of the participants $(N=51)$ completed some higher education to a master's degree. Finally, participants disclosed earning annual incomes ranging between $\$ 2,400$ and $\$ 53,000(M=\$ 26,457.69)$, and $86.5 \%$ of them indicated part-time employment statuses. 
Table 1. Sociodemographic Characteristics of Participants ( $\mathrm{N}=52)$

\begin{tabular}{|c|c|c|}
\hline Characteristic & $n$ & $\%$ \\
\hline \multicolumn{3}{|l|}{ Sex/gender } \\
\hline Male & 24 & 46.2 \\
\hline Female & 28 & 53.8 \\
\hline \multicolumn{3}{|l|}{ Race } \\
\hline White & 26 & 50.0 \\
\hline Black & 1 & 1.9 \\
\hline Asian & 4 & $7 \cdot 7$ \\
\hline Hispanic/Latino & 3 & 5.8 \\
\hline Mixed & 18 & 34.6 \\
\hline \multicolumn{3}{|l|}{ Age } \\
\hline $18-20$ & 14 & 26.9 \\
\hline $21-30$ & 25 & 48.1 \\
\hline $31-40$ & 9 & $17 \cdot 3$ \\
\hline $41-48$ & 4 & $7 \cdot 7$ \\
\hline \multicolumn{3}{|l|}{ Highest level of education } \\
\hline High school diploma & 1 & 1.9 \\
\hline Some 2-year college & 10 & 19.2 \\
\hline Associate's degree & 3 & 5.8 \\
\hline Culinary arts degree & 4 & $7 \cdot 7$ \\
\hline Some 4-year college & 20 & 38.5 \\
\hline Bachelor's degree & 12 & 23.1 \\
\hline Master's degree & 2 & 3.8 \\
\hline \multicolumn{3}{|l|}{ Annual income } \\
\hline$<\$ 10,000$ & 4 & $7 \cdot 7$ \\
\hline$\$ 10,000-\$ 20,999$ & 18 & 34.6 \\
\hline$\$ 21,000-\$ 30,999$ & 11 & 21.2 \\
\hline$\$ 31,000-\$ 40,999$ & 14 & 26.9 \\
\hline$\$ 41,000-\$ 50,000$ & 2 & 3.8 \\
\hline$>\$ 50,000$ & 3 & 5.8 \\
\hline \multicolumn{3}{|l|}{ Employment status } \\
\hline Part-time & 45 & 86.5 \\
\hline Full-time & 7 & 13.5 \\
\hline \multicolumn{3}{|l|}{ Years worked } \\
\hline $2-5$ & 20 & 38.5 \\
\hline $6-10$ & 14 & 26.9 \\
\hline $11-15$ & 11 & 21.1 \\
\hline $16-20$ & 3 & 5.8 \\
\hline $21-25$ & 4 & $7 \cdot 7$ \\
\hline
\end{tabular}




\section{Data Analysis and Presentation}

Adopting a constructivist grounded theory approach (Charmaz, 2008), I view knowledge as inductive, reflexive, and socially produced. A major strength of qualitative data is the comprehensive story it can tell about people's interpretation of their experiences in social contexts (Berg, 2001). Moreover, in-depth interviews allow researchers to hear people's detailed accounts of behaviors, motives, and opinions from their perspectives (Rubin \& Rubin, 2012). Therefore, during the data analysis process, I listened to the interviews multiple times and transcribed them verbatim-noting pauses, intonation, expressions, and gestures.

Additionally, in the results section, I present the interviewees' complete, verbatim, block-quote responses, albeit sometimes lengthy, to give voice to those who are often hushed or silenced, thereby allowing them to tell their stories (see Charmaz, 2006; Holstein \& Gubrium, 2008).

After I completed interview transcription, I undertook several rounds of open and focused coding. I initially coded for broad topics (e.g., substance use or stressful experiences) and later coded for concepts and phrases that were more specific, e.g., "shift shots" or "driving under the influence (DUI)." Throughout the coding process, I noted, examined, and established meaningful categories and themes with memo writing (Charmaz \& Belgrave, 2012). Before feeling comfortable with my conclusions, I cross-checked and confirmed information with fieldnotes, key informants, and national statistics.

\section{Results}

\section{Descriptive Statistics}

The data showed a prevalence of risky health behaviors among restaurant employees. Specifically, workers engaged in heavy alcohol consumption, cigarette smoking, drug use, and driving while under the influence of substances. Not only did employees in the sample disclose their own substance use, they also reported coworkers who participated in adverse health behaviors. Aside from tobacco and alcohol use, participants divulged recreational marijuana, cocaine, ecstasy/MDMA, and prescription drug use. While these health issues may not initially have a direct effect on the workers' lives, each health risk has potential short-term and long-term adverse consequences.

Table 2 shows the number and percent of participants who revealed using different substances. Among the sample, 42.3\% smoked cigarettes, $100 \%$ consumed alcohol, 86.5\% used marijuana, $23.1 \%$ used cocaine, $28.8 \%$ used ecstasy/MDMA, and 15.4\% recreationally used prescription drugs, such as Adderall or Vicodin. In addition to self-reported substance use, all of the participants discussed coworkers who used tobacco, alcohol, illicit drugs, and prescription drugs.

Table 2. Restaurant Employees' Self-Reported Substance Use ( $\mathrm{N}=52)$

\begin{tabular}{lcc}
\hline \multicolumn{1}{c}{ Substance } & $\boldsymbol{n}$ & $\mathbf{\%}$ \\
\hline Cigarettes & 22 & 42.3 \\
Alcohol & 52 & 100.0 \\
Marijuana & 45 & 86.5 \\
Cocaine & 12 & 23.1 \\
Ecstasy/MDMA & 15 & 28.8 \\
Recreational prescription drugs & 8 & 15.4 \\
\hline
\end{tabular}


Table 3 indicates the frequency (number and percent) at which the participants used cigarettes, alcohol, and marijuana; however, it does not provide the frequency of the other disclosed substances because participants typically used these sporadically. Participants varied in substance use by indicating daily, weekly, monthly, or annual consumption. In terms of high frequency, 32.7\% used cigarettes, $57.7 \%$ consumed alcohol, and $38.6 \%$ used marijuana on a daily basis.

Table 3. Restaurant Employees' Self-Reported Frequency of Substance Use $(\mathrm{N}=52)$

\begin{tabular}{|c|c|c|}
\hline Substance & $n$ & $\%$ \\
\hline \multicolumn{3}{|l|}{ Cigarettes } \\
\hline Daily & 17 & 32.7 \\
\hline Weekly & 2 & 3.8 \\
\hline Monthly & 2 & 3.8 \\
\hline Annually & 1 & 1.9 \\
\hline None & 30 & $57 \cdot 7$ \\
\hline \multicolumn{3}{|l|}{ Alcohol } \\
\hline Daily & 30 & 57.7 \\
\hline Weekly & 15 & 28.8 \\
\hline Monthly & 6 & 11.5 \\
\hline Annually & 1 & 1.9 \\
\hline None & o & 0.0 \\
\hline \multicolumn{3}{|l|}{ Marijuana } \\
\hline Daily & 20 & 38.6 \\
\hline Weekly & 9 & $17 \cdot 3$ \\
\hline Monthly & 10 & 19.2 \\
\hline Annually & 6 & 11.5 \\
\hline None & 7 & 13.5 \\
\hline
\end{tabular}

Table 4 highlights the number of self-reported legal citations for DUI. All participants were aware of at least one coworker with a DUI, the vast majority of the participants $(N=40)$ reported they were privy to three or more coworkers with a DUI, and 11 (21.1\%) participants had one or more DUIs. Even when participants disclosed not having a DUI, they discussed their as well as coworkers' experiences driving while under the influence of substances. In sum, the participants mentioned that they and coworkers partook in excessive alcohol consumption, had DUI citations, and drove while under the influence of substances despite possible hazards.

Table 4. Restaurant Employees' Self-Reported Penal Sanctions for Driving Under the Influence (DUI; N =52)

\begin{tabular}{ccc}
\hline DUI Penal Sanctions & $\boldsymbol{n}$ & $\mathbf{\%}$ \\
\hline O & 41 & 78.87 \\
1 & 9 & 17.3 \\
2 & 1 & 1.9 \\
3 & 1 & 1.9 \\
\hline
\end{tabular}


Shigihara, 2020

\section{Restaurant Socialization, Friendships, and Personnel Policies: Pathways to Health Risks}

Beyond descriptive statistics detailing the number and percentage of participants' risky health behaviors, indepth qualitative data expand our understanding of how and why employees potentially jeopardize their wellbeing. The participants' lived experiences and narratives expose social processes of and pathways to health dangers. Results indicate that restaurant culture normalizes adverse health behaviors, especially substance use, among employees. Specific characteristics of restaurants that allow and often encourage health risks include restaurant socialization, friendships, and personnel policies. Therefore, this section analyzes and explains the topic of health risks in restaurants with the theoretical framework of "professional back places," or workplaces where employees may participate in norm transgressions with minimal to no formal or informal discipline (Shigihara, 2018b). I argue that restaurants are professional back places, and as such, generally shield norm transgressors from occupational sanctions, community members, the criminal justice system, and social disgrace. Throughout the interviews, participants described specific restaurant-work features as facilitators of adverse health behaviors, which shaped health risks as conventional practice. In accordance with my (Shigihara, 2018b) findings about employee theft in restaurants, the "workplace shields" of socialization, friendships, and personnel policies, for the most part, protect restaurant employees from the reprimand, disapproval and contrition of risky health behaviors. Below, I discuss each of these workplace shields as applied to employee health risks and provide in-depth participant narratives detailing experiences with substance use and driving while under the influence of substances.

\section{Socialization}

Generally, socialization includes the ways in which people learn and internalize the norms, values, and beliefs in a social group (Grusec \& Hastings, 2015). Although there are several types of socialization, workplace socialization (Shigihara, 2018b) is all the ways in which people learn (and attempt) to align their behaviors with occupational norms. Workplace socialization thus occurs as soon as people enter a job. For example, people learn occupational duties, how to interact with coworkers or customers, and appropriate workplace decorum. In the scope of this article, I refer to socialization relative to learning and internalizing coping mechanisms for workplace stress. Specifically, the participants underscored their need to cope with the highly stressful work environment in restaurants, and they discussed methods they used to alleviate such stress. After people enter and spend time in restaurants, workplace socialization affords restaurant workers the informal permission to use substances to cope; it also shields them from reprimand or feelings of impropriety.

Cocaine, marijuana, cigarettes, and booze, all common in the restaurant industry. I do it after work to help me relax, and on my days off. I enjoy the cannabis, and I do like to drink. I smoke two, three, four [cigarettes] a day, depending on what I'm drinking, or if I'm doing other stuff. I like riding the train high on cocaine. I like to play in the snow. Doing ski passes is my thing [laughs]. (Guido, 28, server, lead trainer, expeditor, bartender, cook)

The restaurant is a very high intense stress level environment. I feel like it's war. I think I read somewhere about the top five careers that had alcoholics, and servers were in the top five. I can totally see that. The stress [pause] sometimes you just can't unwind your mind, it just spins and spins and spins. I think moving so fast when you're working, it doesn't stop, and I think that's why people have to go out and unwind, and vent, and drink. (Cindy, 33, server, shift manager)

I think drinking is kind of a pre-req for working in the restaurant industry, like you know, 'cause you gotta deal with assholes all day, so you know pretty much the thing you have in common with everybody else there is you want to go out and blow off some steam at the end. Pretty much at every restaurant that I've worked at, pretty much all the workers have drank and smoked, so yeah, that has been my personal experience. And you know, there are a lot of DUIs, public transportation ain't 
exactly the best, and you know cabs are pretty pricey, so eventually everyone slips up every now and then, and has a run in with old Johnny Law so. (Seymour, 25, server, bartender, shift manager)

\section{Friendships}

Workplace friendships are the peer groups that teach and encourage occupational norms (Shigihara, 2018b). In restaurants, friendships and strong bonds develop quickly because of the highly social work environment. Friendships in restaurants encourage unhealthy behaviors and shield employees from the shame and remorse of adverse health practices. For instance, coworkers normalize substance use, partying, and driving while under the influence of substances by speaking about these behaviors in a commonplace, nonchalant, or humorous manner. Ultimately, although health risks can lead to life threatening circumstances, workplace friends enable alcohol consumption, drug use, as well as driving after using substances.

We would go to places like large sports bars that didn't card you because they know you so well because you go there every day after work, so they're not gonna card you 'cause they know you. We would go to bars where my coworkers knew the bartenders, and they would give us free drinks, and also we went to places that my coworkers knew I could get into, places that I could get alcohol at. (Erika, 20, host, food runner)

There was a time when I worked across the street. You come home from work, you got your restaurant crew, you sit and you drink, and you smoke, and you snort [cocaine], and you party, and the next thing you know it's six am. Then, you all take a nap until two the next afternoon, you get up, you go to work, and do it all over again. (Val, 39, server, shift manager)

\section{Personnel policies}

Workplace personnel policies are the guidelines that govern occupational norms (Shigihara, 2018b). In restaurants, informal and formal personnel policies (or lack thereof) facilitate risky health behaviors. Stated differently, lenient rules and limited to no sanctions encourage substance use on and off the job, which may result in driving while under the influence of substances. Relative to alcohol consumption, restaurant workers often socialize and drink before work, on the job, after work, and outside of work. Despite rules about not drinking before or during work and rules about drinking after work, participants reveal how these rules are rarely enforced. Many restaurant personnel (e.g., managers or bartenders) even provide employees alcoholic beverages during or after shifts. Moreover, in spite of strict or zero-tolerance policies on illegal substances, the employees in the sample divulge illicit drug use prior to, during, or after work.

I've known a lot of workers with DUIs. I worked with one guy in particular at this fine dining restaurant who was an older man who had seven DUIs. It's common. I have a drinking in public citation. Other than alcohol, a good amount of servers are potheads, like they smoke marijuana. It's not uncommon at all for a staff member to come in stoned. I have done that. I smoke a fair amount of marijuana. One thing that I've never participated in that I know also happens is workers doing cocaine. I guess I understand it 'cause you need energy to work, and I'm sure cocaine gives you that, a pick me up, because working is tiring. I've definitely seen bartenders drink on the job, I have drank on the job before. At one restaurant I worked at, it was a pretty commonplace to just have a shot, or ask a bartender for a drink. You know, put the shot in a to go cup. It's not like you get drunk, you have a drink, it takes the edge off. I don't think it's such a big deal, like you have a drink you know, it relaxes you. In some restaurants, it's okay, like some let you have shots with the guests, like some bartenders are allowed to do that, I'm not saying it's okay, but I mean if you have a drink while you're working, if it's allowed, it isn't such a big deal, but if you're not allowed to, you're breaking the rules. (Ted, 25, server, bartender, shift manager) 
At the restaurant I work at now, everyone is really happy because the whole motto is the employee first, and the customer is not always right, not to an extreme, but you know, the employee comes first. So we have parties, we have staff parties, we do staff shots during the shift. Everyone who has worked there has really worked there for a long time, and it's a place that really just treats its employees well, and the owner knows everyone's name. We feel very well treated as employees, we come in with family and we get 50 percent off, we get 50 percent off our food at night if we want to order food, and we get 3 staff drinks after work. These things just make you feel valued as an employee. We get staff shots during the shift, they're very open to us having fun. It is really liberal in terms of any rules at my restaurant. They really push us to be involved with our guests and staff members [pause], so say I have a friend come in, and I haven't seen them in a long time, I can ring in a round of shots and do them at the table with them and that will be on the house. Or, if I have a friend come in, and they want to do a shot of whiskey with me, they can buy me a shot of Whiskey, and I am allowed to do that shot with them right at the table or at the bar. I mean we are all kinda "professional drinkers," we all kinda know our limits, and we know when to stop, and we are allowed to get a little bit tipsy. It is really a matter of being able to do your job and knowing your limits. Some of the staff keep bottles of liquor with them at the restaurant and have a shot every once and a while. The rules are not set in stone about drinking [pause] it is basically, don't fuck up! You can have a shot here and there, just don't get wasted and screw up essentially. (Lucie, 23, busser, host, food runner, bar back, server)

\section{Discussion and Conclusion}

The present study examined substance use and risky health behaviors among restaurant workers. It also addressed how and why restaurant workers participant in taking health risks. Up until now, there has been a limited amount of in-depth qualitative research on adverse health behaviors among restaurant workers. Moreover, minimal research has explored the self-reported processes within restaurants that explain pathways to substance use and driving while under the influence of substances. This research helps to fill the gap of knowledge on the sociocultural characteristics of restaurant work that influence health behaviors. This article brought attention to a wide variety of restaurant industry employees as well as how they talk about taking health risks. Doing so, this study broadens the theoretical explanation for norm transgressions in the service sector. In particular, as professional back places (Shigihara, 2018b), restaurants generally protect and shield employees from the shame and rebuke of deviant health behaviors.

Similar to findings in past studies (Bush \& Lipari, 2015; Hight \& Park, 2018; Pizam, 2012), the present study suggests that restaurant industry workers exhibit high levels of substance use. Expanding the substance use and workplace literature, this research underscores a high prevalence of restaurant employees driving while under the influence of substances regardless of whether they have received a formal DUI citation. Consistent with research indicating that job stress contributes to substance use among employees (e.g., Hight \& Park, 2019; Lehman \& Bennett, 2002), the results showed that restaurant workers use substances (i.e., alcohol, cigarettes, marijuana, and other drugs) to cope with occupational stress. This research also supports past findings that connect risky health behaviors with lax work settings, norms and values, little fear of formal sanctions, substance accessibility, and inadequate prevention policies (Bryant, 1974; Buvik \& Scheffels, 2019; Frone \& Windle, 1997; Kitterlin, 2015; Trinkoff et al., 2000).

This study provides insight into how workplace socialization, friendships, and personnel policies relate to substance use and driving while under the influence of substances. It also attends to Berkman et al.'s (2000) call for research on how social networks influence health outcomes. Specifically, the research findings evolve how learned and internalized worker coping mechanisms, friends at work, and workplace rules and guidelines enable and encourage risky health behaviors. These results are in line with research that indicates heavy drinking increases when workers socialize with coworkers (Moore et al., 2009) and drink after work 
(Kjaerheim et al., 1995; Moore et al., 2012), and highlight that drug use and driving while under the influence of substances also occur when coworkers socialize. Moreover, as Kjaerheim et al. (1997) found that stress mediated by the inability to relax after work was associated with heavy drinking, the participants in this study divulged drinking and drug use because of the stress of restaurant work as well as the inability to "unwind."

Although this study develops the understanding of substance use in workplaces, there are some limitations to it. First, while some research proposes that substance use precedes people's employment entrance (Paternoster et al., 2003), and other research contends that substance use succeeds employment entrance (Ames \& Janes, 1992), the current study cannot settle whether restaurant workers used substances prior to entering the restaurant industry or began using substances after entering. However, the data indicate that workplace factors, such as free drinks, substance accessibility, and lack of prevention policies, often promote substance use.

Second, despite the depth of qualitative data collected, I was not able to consider or address all possible factors that influence substance use and driving while under the influence of substances among restaurant workers (e.g., family stress). Regardless, this research contributes to the knowledge of health behaviors among restaurant workers and pathways to unhealthy practices.

Third, this study occurred over a 5-year period, and thus does not have the ability to address issues of later life disease, mortality, or negative personal/societal effects. Accordingly, prospective scholars ought to conduct longitudinal research on restaurant employees' health behaviors and life outcomes.

Fourth, although the sample includes a large group of people from diverse backgrounds, the findings in this article are not generalizable to all restaurant workers in the United States. Still, it is important to note that the research analyses are applicable to many other workplace settings that involve high stress, a fast pace, nontraditional work hours, minimal rewards, strong social networks, and/or inadequate substance use prevention policies. To explore current study results elsewhere, future researchers might examine socialization, friendships, and personnel policies as related to risky health behaviors in other restaurants as well as in other service-sector industries, such as in entertainment, leisure, hospitality, and retail.

Studies reveal that employee substance use is linked to health issues, driving while under the influence of substances, accidents on the jobs, poor service, lack of work cohesion, increased work and stress for coworkers, workplace costs, and high turnover rates (Bush \& Lipari, 2015; Degenhardt \& Hall 2012; Ghodse, 2005; Horgan et al., 2001; Kaminski et al., 2019; Moore, 1998). Research also indicates that workplace wellbeing programs and classes are important for employees because workers report feeling emotionally, physically, and mentally stable after participating in them (Edwards \& Marcus, 2018). Therefore, in addition to the mentioned research implication, this study fosters ideas about how to improve restaurant industry and employee well-being.

To prevent or at least reduce restaurant employee substance use and driving while under the influence of substances, I present the following policy recommendations for positive social change in terms of personal, social, and job-related well-being. First, restaurant workers should go through annual training programs about service industry substance use and abuse prevention, effects of substance use and abuse, alcohol and substance use safety, underage drinking, and driving while under the influence of substances. Such programs could generate substance use and abuse awareness and possibly curtail short-term and long-term adverse health outcomes.

Second, restaurant owners and managers should consider eliminating policies that provide employees free (or easy access to) alcohol before, during, and after work to diminish work-aided health risks and DUIs. Third, restaurants should encourage and engage its employees in healthy stress prevention, coping mechanisms, conflict resolution, social activities, coworker socialization, and ride sharing or public transportation practices 
when using substances. Healthy workplace culture might inspire longstanding employee stability and positive well-being. Finally, restaurants should continue heading in the direction of higher wages and improved fringe benefits to decrease employee stress and subsequent unhealthy coping mechanism, as research shows that low wages and job instability are associated with psychological distress, poor sleep quality, and unhappiness (Schneider \& Harknett, 2019).

\section{References}

Adler, P., \& Adler, P. (1987). Membership roles in field research. Sage.

Ames, G. M., \& Janes, C. (1992). A cultural approach to conceptualizing alcohol and the workplace. Alcohol Health \& Research World, 16, 112-119.

Anthony, J. C., Eaton, W., Mandell, W., \& Garrison, R. (1992). Psychoactive drug dependence and use: More common in some occupations than others? Journal of Employee Assistance Research, 1, 148-186.

Becker, H., \& Geer, B. (1960). The analysis of qualitative field data. In R. Adams \& J. Preiss (Eds.), Human organization research (pp. 652-660). Dorsey.

Berg, B. L. (2001). Qualitative research methods for the social sciences. Allyn and Bacon.

Berkman, L. F., Glass, T., Brissette, I., \& Seeman, T. E. (2000). From social integration to health: Durkheim in the new millennium. Social Science \& Medicine, 51, 843-857.

Biernacki, P., \& Waldorf, D. (1981). Snowball sampling: Problems and techniques of chain referral sampling. Sociological Methods and Research, 10, 141-163.

Bryant, C. D. (1974). Deviant behavior: Occupations and organizational bases. Rand McKally.

Bush, D. M., \& Lipari, R. N. (2015). The CBHSQ report: Substance use and substance use disorder by industry. Substance Abuse and Mental Health Services Administration.

Buvik, K., \& Scheffels, J. (2019). On both sides of the bar. Bartenders' accounts of work-related drinking. Drugs: Education, Prevention \& Policy. Advance online publication. https://doi.org/10.1080/09687637.2019.1601160

Charmaz, K. (2006). Constructing grounded theory: A practical guide through qualitative analysis. Sage.

Charmaz, K. (2008). Shifting the grounds: Constructivist grounded theory methods. In Morse, J. M., Stern, P. N., Corbin, J., Bowers, B., \& Charmaz, K., Clarke, A. E. (Eds.), Developing grounded theory (pp. 127193). Left Coast Press.

Charmaz, K., \& Belgrave, L.L. (2012). Qualitative interviewing and grounded theory analysis. In Gubrium, J. F., Holstein, J. A., Marvasti, A. B., McKinney, K. D. (Eds.), The sage handbook of interview research (pp. 347-366). Sage.

Degenhardt, L., \& Hall, W. (2012). Extent of illicit drug use and dependence, and their contribution to the global burden of disease. Lancet, 379, 55-70.

Dimich-Ward, H., Gallagher, R. P., Spinelli, J. J., Threlfall, W. J., \& Band, P. R. (1988). Occupational mortality among bartenders and waiters. Canadian Journal of Public Health, 79, 194-197.

Edwards, A. V., \& Marcus, S. (2018). Employee perceptions of well-being programs. Journal of Social, Behavioral, and Health Sciences, 12, 100-113.

Fine, G. A. (1996). Kitchens: The culture of restaurant work. University of California Press.

French, J. R., Kahn, R. L., \& Mann, F. C. (1962). A programmatic approach to studying the industrial environment and mental health. Journal of Social Issues, 3, 1-47. 
Frone, M. R., \& Windle, M. (1997). Job dissatisfaction and substance use among employed high school students: The moderating influences of active and avoidant coping styles. Substance Use \& Misuse, $32,571-585$.

Gatta, M. L. (2002). Juggling food and feelings emotional balance in the workplace. Lexington Books.

Ghodse, H. (2005). Addition at work: Tacking drug use and misuse in the workplace. Gower Publishing.

Giousmpasoglou, C., Brown, L., \& Cooper, J. (2018). Alcohol and other drug use in michelin starred kitchen brigades. International Journal of Hospitality Management, 70, 59-65.

Goffman, E. (1963). Stigma: Notes on the management of spoiled identity. Simon \& Schuster.

Grandey, A. A., Frone, M. R., Melloy, R. C., \& Sayre, G. M. (2019). When are fakers also drinkers? A selfcontrol view of emotional labor and alcohol consumption among U.S. service workers. Journal of Occupational Health Psychology, 24, 482-497.

Grusec, J., \& Hastings P. D. (2015). Handbook of socialization: Theory and research. Guilford Press.

Hight, K. S., \& Park, J. Y. (2018). Substance use for restaurant servers: Causes and effects. International Journal of Hospitality Management, 68, 68-79.

Hight, K. S., \& Park, J. Y. (2019). Role stress and alcohol use on restaurant server's job satisfaction: Which comes first? International Journal of Hospitality Management, 76, 231-239.

Hoffman, J. P., Brittingham, A., \& Larison, C. (1996). Drug use among U.S. workers: Prevalence and trends by occupation and industry categories. Substance Abuse and Mental Health Services Administration.

Holahan, C., \& Moos, R. H. (1987). Personal and contextual determinants of coping strategies. Journal of Personality \& Social Psychology, 52, 946-955.

Holstein, J. A., \& Gubrium, J. F. (2008). Handbook of constructionist research. The Guilford Press.

Horgan, C., Skwara, K. C., Strickler, G., \& Andersen, L. (2001). Substance abuse: The nation's number one health problem. Robert Wood Johnson Foundation.

Kaminski, K., Kitterlin-Lynch, M., Cain, L., \& Beckman, E. (2019). Drug use and its perceived consequences: A comparison of foodservice and non-foodservice employees. International Journal of Hospitality Management, 77, 238-244.

Karasek, R. (1979). Job demands, job decision latitude, and mental strain: Implications for job redesign. Administrative Science Quarterly, 24, 285-307.

Karasek, R., \& Theorell, T. (1990). Healthy work: Stress, productivity, and the reconstruction of working life. Basic Books.

Kitterlin, M. (2015). Foodservice employee substance abuse: Is anyone getting the message? International Journal of Contemporary Hospitality Management, 27, 810-826.

Kjaerheim, K., Mykletun, R., Aasland, O. G. (1997). Work-related stress, coping resources, and heavy drinking in the restaurant business. Work and Stress, 11, 6-16.

Kjaerheim, K., Mykletun, R., Aasland, O. G., Haldorsen, T., \& Anderson, A. (1995). Heavy drinking in the restaurant business: The role of social modeling and structural factors of the work-place. Addiction, $90,1487-1495$.

Kjaerheim, K., Mykletun, R., \& Haldorsen, T. (1996). Selection into the restaurant business on personality characteristics and the risk of heavy drinking. Personality and Individual Differences, 21, 625-629.

Kochanek, K. D., Murphy, S. L., Xu, J., \& Arias, E. (2019). Deaths: Final data for 2017. National Vital Statistics Reports, 68, 1-77. 
Larsen, S. (1994). Alcohol use in the service industry. Addiction, 89, 733-741.

Lazarus, R. S. (1966). Psychological stress and the coping process. McGraw-Hill.

Lee, J. D., \& Craft, E. A. (2002). Protecting one's self from a stigmatized disease...once one has it. Deviant Behavior, 23, 267-299.

Lehman, W. E. K., \& Bennett, J. B. (2002). Job risk and employee substance use: The influence of personal background and work environment factors. The American Journal of Drug and Alcohol Abuse, 28, $263-286$.

Leigh, P. J. (1991). A ranking of occupations based on the blood pressures of incumbents in the National Health and Nutrition Examination Survey I. Journal of Occupational Medicine, 33, 853-862.

Leigh, P. J., \& Jiang, W. (1993). Liver cirrhosis deaths within occupations and industries in the California occupational mortality study. Addiction, 88, 767-779.

Mandell, W., Eaton, W., Anthony, J., \& Garrison, R. (1992). Alcoholism and occupations: A review and analysis of 104 occupations. Alcoholism, 16, 734-746.

McGrath, J. E. (1970). Social and psychological factors in stress. Holt, Rinehart, and Winston.

Moore, R. S. (1998). The hangover: An ambiguous concept in workplace alcohol policy. Contemporary Drug Problems, 25, 49-63.

Moore, R. S., Ames, G. M., Duke, M. R., \& Cunradi, C. B. (2012). Food service employee alcohol use, hangovers and norms during and after work hours. Journal of Substance Use, 17, 269-276.

Moore, R. S., Cunradi, C. B., \& Duke, M. R. (2009). Dimensions of problem drinking among young adult restaurant workers. The American Journal of Drug and Alcohol, 35, 329-333.

Nusbaumer, M. R., \& Reiling, D. M. (2002). Environmental influences on alcohol consumption practices of alcoholic beverage servers. The American Journal of Drug and Alcohol Abuse, 28, 733-742.

National Highway Traffic Safety Administration. (2017). Traffic safety facts. https://crashstats.nhtsa.dot.gov/Api/Public/ViewPublication/812450

National Restaurant Association (NRA). (2019). News and research. https://restaurant.org/research

Pampel, F. C. (2006). Socioeconomic distinction, cultural tastes, and cigarette smoking. Social Science Quarterly, 87, 19-35.

Paternoster, R., Bushway, S., Brame, R., \& Apel, R. (2003). The effect of teenage employment on delinquency and problem behavior. Social Forces, 82, 297-335.

Pidd, K., Roche, A. M., Fischer, J. A., \& McCarthy, C. (2014). Risky behaviours, risky work settings: The alcohol and drug consumption patterns, health and wellbeing of commercial cookery trainees. Journal of Health, Safety, and Environment, 30, 301-311.

Pizam, A. (2010). Alcoholism among hospitality employees. International Journal of Hospitality Management, 29, 547-548.

Pizam, A. (2012). Illicit drug use among hospitality employees. International Journal of Hospitality Management, 31, 631-632.

Redmon, D. (2003). Playful deviance as an urban leisure activity: Secret selves, self-validation, and entertaining performances. Deviant Behavior, 24, 27-51.

Rook, K. S. (1990). Social relationships as a source of companionship: Implications for older adults psychological well-being. In B. R. Sarason, I. G. Sarason, \& G. R. Pierce (Eds.), Social support: An interactional view (pp. 221-250). Wiley. 
Rubin, H., \& Rubin, I.S. (2012). Qualitative interviewing. Sage.

Schneider, D., \& Harknett, K. (2019). Consequences of routine work-schedule instability for worker health and well-being. American Sociological Review 84, 81-114.

Shigihara, A. M. (2015). Strategic adulthood: A case study of restaurant workers negotiating nontraditional life course development. Advances in Life Course Research, 26, 32-43.

Shigihara, A. M. (2018a). (Not) forever talk: Restaurant employees managing occupational stigma consciousness. Qualitative Research in Organizations and Management, 32, 384-402.

Shigihara, A. M. (2018b). Restaurants and deviance: Theft in professional back places. In S. E. Brown \& O. Sefiha (Eds.), Routledge handbook on deviance (pp. 506-518). Taylor \& Francis.

Shigihara, A. M. (2019). I mean, define meaningful! Accounts of meaningfulness among restaurant employees. Qualitative Sociology Review, 15, 106-131.

Strauss, A. (1987). Qualitative analysis for social scientists. Cambridge University Press.

Sudman, S., \& Kalton, G. (1986). New developments in the sampling of special populations. Annual Review of Sociology, 12, 401-429.

Trinkoff, A. M., Zhou, Q., Storr, C. L., \& Soeken, K. L. (2000). Working access, negative proscriptions, job strain, and substance use in registered nurses. Nursing Research, 49, 83-90.

Warren, C. B., \& Karner, T. X. (2010). Discovering qualitative methods. Oxford University Press.

Wesolowski, A. (2016). Serving up stress: Perceived stressors and coping mechanisms of front of house restaurant employees. JUST, 4, 2-10.

Whyte, W. F. (1948). Human relations in the restaurant industry. McGraw-Hill Book Company.

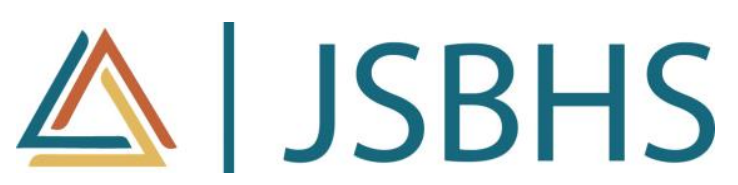

The Journal of Social, Behavioral, and Health Sciences (JSBHS), co-sponsored by the College of Health Sciences and the College of Social and Behavioral Sciences at Walden University, is a peer-reviewed, online, interdisciplinary journal focusing on theoretically-based research that addresses contemporary national and international issues. JSBHS articles include peer-reviewed research reports, brief resports, comprehensive literature reviews, books reviews, and student research. 